У,

ББК 67.407

DOI 10.22394/1682-2358-2021-5-78-87

E.V. Mladenova, postgraduate student of the Service and Labor Law Department, Povolzhsky Institute of Manasement named after P.A. Stolypin, Branch of the Russian Presidential Academy of National Economy and Public Administration

\section{CONCEPT \\ AND PURPOSE \\ OF STATE \\ ENVIRONMENTAL \\ CONTROL (SUPERVISION)}

Regulatory and scientific approaches to understanding environmental control (supervision) are investigated. Special attention is paid to the problem of correlation between the categories "environmental control" and "environmental supervision". The conclusion is made about the need for their differentiation in the legislation.

Key words and word-combinations: environmental control, environmental supervision, environmental protection.
E.B. Младенова, аспирант кафедрь служебного и трудового прања Поволжского института управления имени П.А. Стольпина филиала Российской академии народного хозяйства и государственной службы при Президенте РФ (email: fairy_119@mail.ru)

\section{ПОНЯТИЕ И НАЗНАЧЕНИЕ ГОСУААРСТВЕННОГО ЭКО ОГИЧЕСКОГО КОНТРОАЯ (HAA3OPA)}

Аннотация. Исследуются нормативный и научные подходы к пониманию экологического контроля (надзора). Особое внимание уделяется проблеме соотношения категорий «экологический контроль» и «экологический надзор». Делается вывод о необходимости их дифференциации в законодательстве.

Ключевые слова и словосочетания: экологический контроль, экологический надзор, охрана окружающей среды.

$\mathrm{O}$

Аним из условий развития мюбого правового института явцяется опредеценность и системность в использовании составцяющих его правовых категорий, что позволяет избежкать сложности в правопонимании и правоприменении. Это в полной мере касается и такого правового института, как экологический контроль (налзор). Аля решения обозначенной проблемы требуется проведение научного анамиза сущности и соотношения терминов «экологиче- 
ский контроль» и «экологический надзор», а также изучение подхода законодателя к нормативному закреплению названных дефиниций в законодательстве об охране окружающей среды на предмет опредеменности и системности.

В юридической митературе понятие «контроль» («надзор») не имеет однозначного толкования. В социальном понимании В.С. Основин определяет контроль как осуществление проверки исполнения управменческих решений Амя недопущения отклонений от установленных требований и устранения посмедствий нарушений [1, с. 163-164]. В свою очередь, экологический контроль, по мнению В.В. Петрова, связан с проверкой соблюдения уполномоченными органами требований по охране окружающей природной среды [2, с. 547] .

Как известно, в юридической доктрине основным признаком контрольной деятельности является ее непостоянный, эпизодический характер, при этом контролирующие органы вправе вмешиваться в деятельность подконтрольных субъектов. В научной цитературе преАмагается рассматривать надзор в качестве усеченной разновидности контроля, которая охватывает только такой элемент контроля, как проверка результатов, при этом деятельность поднадзорного субъекта оценивается мишь с позиџии законности, но не цемесообразности [3, с. 3], что не предусматривает возможности вмешательства в его административно-хозяйственную деятельность.

Основными признаками, позволяющими разграничивать контроль и надзор, на взгляд А.В. Мартынова, явцяются следующие: а) их назначение, что предполагает проверку исполнительской дисџиплины со стороны управцяемого субъекта при осушествлении контроця, и надсмотр за правильным поведением субъекта управления при надзоре; 2) пределы административного усмотрения, допустимого при осуществлении контроля за деятельностью управляемого субъекта на преАмет ее целесообразности, и его фактическое отсутствие при наАзоре $[4$, c. $73-83]$.

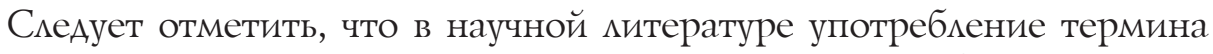
«надзор» часто ассоциируется с надзором прокуратуры. Органами наАзора, как считает В.И. Рохлин, явцяются только органы прокурорского надзора, для которых надзор за исполнением законов становится основной функцией, а все остальные государственные органы, в названии которых содержится термин «наАзор», должны наименоваться органами государственного контромя [5, с. 189].

Вместе с тем особенности правового статуса органов прокуратуры позволяют их дифференцировать с контролирующими органами. К примеру, прокурор может вмешиваться в деятельность поднадзор- 
ного субъекта только при нарушении закона. В отличие от органов прокуратуры контрольно-надзорные органы осуществляют проверку исполнения не только законов, но и подзаконных актов, при этом наАзорная функция аля них не явмяется основной.

К сожкалению, сложилась ситуация, при которой имеется Аублирование полномочий, что не позволяет обеспечить эффективность прокурорской деятельности и требует пересмотра подхода законодателя к решению вопроса четкой дифференциации полномочий и взаимодействия названных органов.

В случае получения прокурором информации о факте экологического правонарушения преАставляется необходимым законодательно предусмотреть обращение прокурора в органы экологического контромя (надзора) с целью выяснения факта наличия аналогичной информации, истребования у контрольно-надзорного органа необходимой информации о проводимых действиях, осуществления контроля за результатами контрольно-надзорных действий. В случае изначального поступления информации о факте совершения экологического правонарушения в органы прокуратуры прокурор должен поручить проведение проверки органу государственного экологического контроля (надзора).

Взаимодействие прокуратуры и органов экологического контроля (надзора) практикуется не только в форме передачи материалов, но и в Аругих формах, в частности, возможно совместное проведение контрольно-надзорных мероприятий, направленных на предупреждение правонарушений.

В отмичие от органов прокуратуры, которые независимы от Аругих государственных органов, осушествляющих государственный контроль, органы экологического контроля зависимы от создавших и уполномочивших их органов, а акты, регламентирующие их деятельность, нере ко противоречат Аруг Аругу [5, с. 188]. Обозначенные признаки показывают справедливость Аифференциации органов государственного контроля и прокурорского надзора, что требует недопушения подмены прокурорами деятельности органов государственного контроля (надзора) при условии обеспечения их взаимодействия.

Как свидетельствует практика, благодаря вмешательству прокуратуры выявляются многочисленные факты нарушений экологического законодательства, что позволяет не допустить причинение серьезного вреда окружаюшей среде. В связи с этим представмяется целесообразным разработать и принять соответствуюшее Положение о взаимодействии прокуратуры и органов экологического контроля (надзора).

Несмотря на дифференциацию в теории административного права категорий «контроль» и «надзор», учитывающую их различное содер- 
жательное назначение, в законодательстве данные термины нередко употребцяются как синонимы, что не соответствует их сути и требует изменения подхода к пониманию. В юридической доктрине контрольная Аеятельность уполномоченных органов исполнительной власти носит непостоянный, эпизодический характер, при этом контролирующие органы уполномочены осуществцять корректировку управленческих решений, связанных с деятельностью подконтрольных объектов. В свою очередь, государственный надзор осуществцяется специализированными органами управления постоянно и систематически и заключается в наблюдении за деятельностью неподчиненных субъектов с цемью выявления нарушений законности [6, с. 111] .

Применительно к государственному экологическому контролю (надзору) необходимо отметить, что проблема соотношения категорий «экологический контроль» и «экологический надзор» в настоящее время не решена, а контрольно-надзорная деятельность в области охраны окружающей среды подвергается вполне обоснованной критике. Так, до 2011 г. в законодательстве об охране окружающей среды в качестве основного вида контрольной деятельности выступал экомогический контроль. ОАнако ввиАу противоречивой и бессистемной государственной политики в области контрольно-надзорной деятельности содержание видов экологического контроля менялось. Такие радикальные изменения происходили в 2011 г., когда нормы Федерального закона «Об охране окружающей среды» о государственном экологическом контроле были заменены нормами об экологическом надзоре.

На том этапе законодатель пошел по пути терминологического разграничения данных категорий по признаку субъектного состава контрольно-наАзорной деятельности: термин «наАзор» распространялся на отношения экологического контроця, осуществцяемого органами исполнительной власти, «контроль» - на отношения произвоАственного и общественного контроля.

Анализ дефиниџии «экологический надзор», содержащейся в п. 1 ст. 65 Федерального закона «Об охране окружаюшей среды», позволяет утвержАать, что Аанное понятие охватывало как экологический контроль, так и надзор [7], поскольку его признаки касались содержания обеих категорий.

С принятием закона-спутника от 11 июня 2021 г. № 170-Ф3 [8] название ст. 65 «Государственный экологический надзор» Федерального закона «Об охране окружающей среды» было изменено на «Государственный экологический контроль (надзор)», что опять же не позволяет разграничить Аанные категории. 
При этом глава XI Закона по-прежннему именуется «Государственный экологический надзор», что явмяется Аоводом, подтвержАающим непоследовательность законодателя. Термин «контроль» все так же применяется только к производственному и общественному контролю в области охраны окружающей среды.

В новом Положении о федеральном государственном экологическом контроле (надзоре) [9], заменившем одноименное Положкение от 8 мая 2014 г. № 426 [10], законодатель снова фактически уравнивает контроль и надзор как виды административной деятельности при осуществлении государственного управления в области охраны окружающее среды.

Поскольку, как выясницось, теоретические модели контроля и наАзора в административно-правовой науке имеют существенные различия, представляется необходимым разграничить данные понятия как в законодательстве, регулируюшем контрольно-надзорные отношения, так и в законодательстве об охране окружающей среды. На наш взгляА, экологический контроль, вкАючающий возможность вмешательства в деятельность подконтрольных субъектов и применение мер принуждения, в большей степени способен оказать положительное воздействие на состояние окружающей среды.

Анализ административно-правовой и специальной китературы по экологическому праву позвоцяет выделить следующие подходы к пониманию экологического контроля (надзора) среди ученых:

1. Государственный экологический контроль (надзор) - мера административно-правовой охраны окружающей среды.

В рамках данного аспекта следует пояснить, что как звено организационно-правового механизма охраны окружающей среды [11, с. 140] государственный экологический контроль (наАзор) служит, по сути, гарантией выполнения обязательных экологических требований.

ОАной из функций экологического контроля (надзора) как правовой меры, наряду с предупредительной и информаџионной, явмяется карательная функция, что нашло отражение в применении к нарушившим правовые экологические требования предусмотренных законодательством санкщий (со ст. 75 Федерального закона «Об охране окружаюшей среды») [12]. Таким образом, посреАством экологического контроля (надзора) обеспечивается принуждение субъектов экологических отношений к соблюдению обязательных требований.

Необходимо отметить, что в юридической митературе существует мнение о необходимости выделения самостоятельной эко- 
мого-правовой ответственности, которая включает все перечисленные виды ответственности за экологические правонарушения [12]. На наш взгляА, рассмотрение «эколого-правовой ответственности» как

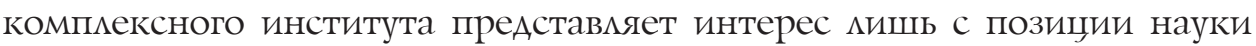
экологического права, но не может быть реализовано в практической пиоскости.

Выявленный по результатам экологического контроля (надзора) ущерб, причиненный окружающей среде, согласно п. 1 ст. 77 Федерального закона «Об охране окружающей среды» и ст. 1064 ГК РФ, подмежит возмещению в полном объеме. Как указал Верховный СуА РФ, государственные органы исполнительной власти (как федеральные, так и региональные), осуществляющие государственный экологический надзор, относятся к числу субъектов, уполномоченных обращаться в суд по делам о нарушениях законодательства в области охраны окружкающей среды и природопользования [13].

2. Государственный экологический контроль (надзор) - функция государственного управления в области охраны окружающей среды.

Гарантируя установленное Конституцией РФ право каждооо «на благоприятную окружающую среду» (ст. 42), государство осуществляет так называемую «экологическую функцию» [14] , составцяющими которой, по мнению Р.Х. Гиззатулина, явцяются «функция охраны природы и рационального природопользования», «функция обеспечения экологической безопасности», «функщия охраны окружающей среды» и т.А., которые отражают отдельные стороны взаимодействия человека и природы. В свою очередь, Аля реализации государством функџии охраны окружающей среды требуется осуществление госуАарственного управления в данной области. Управленческий процесс в Аюбой области государственного управления имеет џиклический характер и проходит ряА стадий, одной из которых и явцяется экологический контроль.

Поскольку экологический контроль - стадия государственного управления в области охраны окружающей среды, Аанный виА контроля может рассматриваться в качестве важнейшей функции государственного управления охраной окружающей среды, осуществляемой специализированными органами исполнительной власти в установленном Правительством РФ порядке [8] .

3. Государственный экологический контроль (надзор) представмяет собой фактор, межащий в основе построения системы и структуры федеральных органов исполнительной власти.

В соответствии с Указом Президента РФ от 9 марта 2004 г. № 314 функции государственного управления явцяются критерием, межащим 
в основе Аифференциации действующей системы федеральных органов исполнительной власти [15]. Так, оАной из подобных управленческих функций явцяется функция по контролю и надзору, осуществление которой требует создания специализированных федеральных органов исполнительной власти, к которым относятся федеральные службы (п. 4 данного Указа Президента РФ).

Примечательно, что еще в советский период в Положении о Горном надзоре от 6 апремя 1922 г. законодатель, демонстрируя понимание различия межАу контрольной и надзорной деятельностью, наАелиц орган горного надзора как контрольными, так и надзорными полномочиями [16, с. 155-172]. Это, как отмечает А.В. Мартынов, стало исторической ошибкой, которая проявцяется и в современном законодательстве, поскольку в нормативных актах, регламентирующих административно-правовой статус федеральных служб, не разграничиваются контрольные и надзорные полномочия [17]. В истории государственного управления всегда существоваци испол-

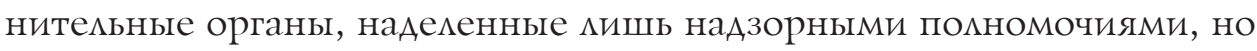
в настоящее время, несмотря на наименования федерацьных служб, содержащих упоминание «надзора», данные федеральные органы исполнительной власти осуществцяют не только надзорные, но и контрольные полномочия. Таким государственным органом в области охраны окружающей среды сегодня, например, явцяется Федеральная служба по экологическому, технологическому и атомному наАзору [18] .

Можно выделить и Аругие подходы, демонстрирующие понимание экологического контроця (надзора). Так, экологический контроль рассматривается в качестве правовой формы экологической деятельности, и в качестве организационного метода осуществления экологической функции государства [19] .

Как уже отмечалось, в современном законодательстве цегальная Аефиниџия экологического контроля содержится в ст. 1 Федерацьного закона «Об охране окружающей среды», исходя из которой контроль в области охраны окружающей среды и экологический контроль понимаются законодателем как равнозначные категории. Вместе с тем Аанная трактовка названных категорий не разделяется единодушно специалистами. Так, по мнению Н.В. Кичигина и О.Ю. Ганюхиной, данные дефиниции соотносятся как цемое и частное: понятие «контроль в обцасти охраны окружающей среАы» вкцючает в себя не только «экологический контроль», но и «природоресурсный контроль» $[20$, c. $6 ; 21$, c. 17$]$.

84 Bulletin of the Volga Region Institute of Administration • 2021. Vol. 21. № 5 
Понятие экологического надзора в силу его отождествления с экомогическим контролем отдельно в специализированном экологическом законе не приводится.

Проводимая в Российском государстве реформа контрольно-наАзорной деятельности связана с принятием Федерального закона от 31 июля 2020 г. № 248-Ф3 «О государственном контроле (надзоре) и муниципальном контроле в Российской Федерации» [22], в котором государственный контроль (надзор) определяется как "деятельность контрольных (надзорных) органов, направленная на предупреждение, выявление и пресечение нарушений обязательных требований, осуществляемая в пределах полномочий указанных органов» (ч. 1 ст. 1), осуществляемая посреАством предусмотренной Законом системы мероприятий, таких как профилактика нарушений обязательных требований, оценка их соблюдения, выявление нарушений, принятие предусмотренных законодательством Российской Федерации мер по пресечению выявленных нарушений, устранение их последствий.

Исходя из данного определения, не только невозможно разграничить деятельность по контролю и надзору, но и, по сути, данное определение позволяет подменять и смешивать данные понятия. ОчевиАно, что комплексное правовое регулирование контроля и наАзора объясняется правовым наследием, когда еще в 2008 г. был принят стратегический Аокумент, в котором Аана установка на ряд преобразований в системе государственного контроля и аАминистративного надзора, связанных с совершенствованием системы контроця и надзора, обеспечением эффективной регламентации деятельности органов государственного контроля (надзора), повышением гарантий субъектов, в отношении которых проводятся мероприятия по контролю (наАзору) [23].

Таким образом, компимяция нормативно закрепленных определений «экологического контроля» и «государственного контроля (надзора)» позволяет сформулировать следующее определение экологического контроля (надзора).

Государственный экологический контроль (надзор) представцяет собой правовую форму экологической деятельности спещиально уполномоченных федеральных или региональных контрольно-надзорных органов в области охраны окружаюшей среды, содержанием которой является реализаџия системы мер, направленных на предотвращение, выявление и пресечение нарушения обязательных требований в области охраны окружающей среды при осушествле- 
нии функции государственного управления в области охраны окружающей среды.

Существующие подходы к пониманию государственного экологического контроля (надзора) позволяют его рассматривать как меру административно-правовой охраны окружающей среды; как правовую форму экологической деятельности; как функщию государственного управления охраной окружаюшей среды; как фактор, обосновывающий построение системы и структуры федеральных органов исполнительной власти.

Противоречивое развитие экологического законодательства, не соответствующее достижениям науки административного права, в котором бессистемно используются термины «экологический контроль» и «экологический надзор», Аолжно быть преодолено, что требует четкого разграничения данных категорий, искмючающего объединение функций контроля и надзора в используемой законодателем терминологии.

\section{Библиографический список}

1. Основин В.С. Основы науки социального управления. Воронеж, 1971.

2. Петров В.В. Экологическое право России: учебник. М., 1996.

3. Кичигин H.B. Правовые проблемы публичного экологического контроля (надзора). М., 2012.

4. Мартынов А.В. Административный надзор в России: теоретические основы построения. М., 2010.

5. Рохлин В.И. Прокурорский надзор и государственный контроль: история, развитие, понятие, соотношение. СПб, 2003.

6. Домрачев Д.Г., Кирилловых А.А. К вопросу о реализации экологического контроля и надзора в Российской Федерации: вопросы теории и практики // Теоретическая и прикладная экология. 2017. № 3.

7. Об охране окружающей среды: Федер. закон от 10 янв. 2002 г. № 7-ФЗ (в ред. от 18 июля 2011 г.) // СЗ РФ. 2002. № 2. Ст. 133; 2021. № 11. Ст. 1704. (данная редакция утратила силу).

8. О федеральном государственном экологическом контроле (надзоре) (вместе с Положением о федеральном государственном экологическом контроле (надзоре): постановление Правительства РФ от 30 июня 2021 г. № 1096. URL: // https://www. garant.ru/products/ipo/prime/doc/401332036/\#review

9. О федеральном государственном экологическом надзоре: постановление Правительства РФ от 8 мая 2014 г. № 426 (в ред. от 21 марта 2019 г.) // СЗ РФ. 2014. № 20. Ст. 2535; 2019. № 14 (ч. 1). Ст. 1515 (утратило силу).

10. Об охране окружающей среды: Федер. закон от 10 янв. 2002 г. № 7-ФЗ (в ред. от 2.июля 2021 г.) // С3 РФ. 2002. № 2. Ст. 133; 2021. № 27 (ч. 1). Ст. 5170.

11. Экологическое право: учебник для бакалавров / под ред. С.А. Боголюбова. 3-е изд., перераб. и доп. М., 2011. 
12. Бринчук М.М. Эколого-правовая ответственность - самостоятельный вид ответственности // Lex russica. 2016. № 6. С. 26-47.

13. О применении судами законодательства об ответственности за нарушения в области охраны окружающей среды и природопользования: постановление Пленума Верховного Суда РФ от 18 окт. 2012 г. № 21 (в ред. от 30 нояб. 2017 г.) // Бюллетень Верховного Суда РФ. 2012. № 12; 2018. № 2.

14. Гиззатулин P.X. Экологическая функция государства: теория и практика реализации: автореф. дис. ... канд. юрид. наук. М., 2014.

15. О системе и структуре федеральных органов исполнительной власти: Указ Президента РФ от 9 марта 2004 г. № 314 (в ред. от 20 нояб. 2020 г.) // СЗ РФ. 2004. № 11. Ст. 945; 2020. № 47. Ст. 7508.

16. История горного надзора в документах XIX-XX веков / под ред. В.В. Грицкова. M., 2004.

17. Мартынов А.В. Административный надзор: теоретические основы построения. М., 2010.

18. О Федеральной службе по экологическому, технологическому и атомному надзору: постановление Правительства РФ от 30 июля 2004 г. № 401 (в ред. от 27 февр. 2021 г.) // С3 РФ. 2004. № 32. Ст. 3348; 2021. № 10. Ст. 1619.

19. Бринчук М.М. Экологическое право: учебник. 2008. [Электронный ресурс]. Доступ из СПС «КонсультантПлюс».

20. Кичигин Н.В. Правовые проблемы муниципального экологического контроля: автореф. дис. ... канд. юрид. наук. М., 2004.

21. Ганюхина О.Ю. Правовое регулирование экологического контроля в Российской Федерации: автореф. дис. ... канд. юрид. наук. Саратов, 2007.

22. О государственном контроле (надзоре) и муниципальном контроле в Российской Федерации: Федер. закон от 31 июля 2020 г. № 248-Ф3 // С3 РФ. 2020. № 31 (ч. 1). Ст. 5007.

23. О Концепции долгосрочного социально-экономического развития Российской Федерации на период до 2020 года: распоряжение Правительства РФ от 17 нояб. 2008 г. № 1662-р (в ред. от 28 сент. 2018 г.) (вместе с Концепцией долгосрочного социально-экономического развития Российской Федерации на период до 2020 года) // СЗ РФ. 2008. № 47. Ст. 5489. 